\title{
SHRIMP FARMERS' COMPETENCE AND TRAINING NEEDS ON CLIMATE CHANGE ADAPTATION: A CASE STUDY FROM SOUTHWEST COASTAL BANGLADESH
}

\author{
Md. Sabbir Ahsan ${ }^{1}$, Md. Ali Akber ${ }^{1}$, , Md. Atikul Islam ${ }^{1}$, Md. Munsur Rahman ${ }^{2}$, and \\ Mohammad Rezaur Rahman ${ }^{2}$ \\ ${ }^{1}$ Environmental Science Discipline, Khulna University, Khulna, Bangladesh. \\ ${ }^{2}$ Institute of Water and Flood Management (IWFM), Bangladesh University of Engineering and Technology \\ (BUET), Dhaka, Bangladesh.
}

\begin{abstract}
Sustainability of shrimp farming is important for both environmental and economic benefits of Bangladesh. The Department of Fisheries provides training to the shrimp farmers; however, techniques on adaptation to climate change are not adequately addressed in the training. This study assessed the competence and training needs of shrimp farmers on climate change adaptation. Two groups of shrimp farmers (each group consisting of 50 individuals) were surveyed and 20 key informants were interviewed from Kaikhali and Ramjannagar unions of Shyamnagar subdistrict under Satkhira district in southwest Bangladesh. Group A included shrimp farmers who had recently participated in training, and group B (control group) included shrimp farmers who had never attended a similar training and had no contact with the shrimp farmers of Group A. Borich Needs Assessment Model was used to assess the training needs of the shrimp farmers. Both of the groups imposed high importance on the skills for adaptation to climate change, but Group A had high competence and Group B had moderate competence. The top three training needs for both of the groups were: a) controlling fluctuation of salinity, b) management for heavy rainfall, and c) management for drought. Shrimp farmers of southwest coastal Bangladesh need more training support for adaptation to climate change.
\end{abstract}

Keywords: shrimp farming; training needs; Borich Needs Assessment Model, climate change; Bangladesh

\section{Introduction}

Bangladesh is geographically suitable for brackish water shrimp farming because of the $710 \mathrm{~km}$ of coastline, estuaries of numerous rivers and low-lying tidal flood plains(Alam et al., 2005; USAID, 2006). Commercial shrimp farming has undergone rapid expansion in the southwest coastal districts since 1980s, which was mostly attributable to higher economic return, low-wage of local labours and expanding global demand (Afroz and Alam, 2013; Swapan and Gavin, 2011). Shrimp industry represents the second largest export industry for Bangladesh after garments sector (Paul and Vogl, 2012). At present, Bangladesh has approximately 275,583 ha of coastal shrimp farms producing an average of 75,167 metric tons of shrimp annually with an average production rate of $370 \mathrm{~kg} / \mathrm{ha} / \mathrm{year}$ (Ahmed and Glaser, 2016; Gammage et al., 2006; Sohel and Ullah, 2012).

Shrimp and prawn farming started in coastal area of Bangladesh in 1970s(Azad et al., 2009); however, rapid expansion occurred since 1980s(Ahmed and Glaser, 2016). More than 75\% of prawn and shrimp farms (locally known as 'gher') are located in southwest Bangladesh mainly in Bagerhat, Khulna and Satkhira districts, with the remainders in the southeast region including Cox's Bazar and Noakhali districts(Ahmed, 
2013). The shrimp industry employs approximately 1.2 million people for shrimp production, processing and marketing activities. About 4.8 million Bangladeshi directly depend on this sector for their livelihood(Paul and Vogl, 2012).

Bangladesh is one of the most vulnerable countries to global climate change (Harmeling and Eckstein, 2012; Kreft and Eckstein, 2013). Different climatic variables, including temperature, rainfall, salinity, drought, flood and cyclone pose serious threat to shrimp production (Ahmed and Glaser, 2016). Few of the shrimp diseases are the direct result of climatic extreme, while other diseases are triggered due to the stress induced by the climatic extreme like drought (Hossain et al., 2013). Local shrimp farmers are taking various adaptation measure to cope up with the impacts of changes of climatic variables. These include water exchange, feeding practice, lime application, adjusted harvest, dyke height increase, netting around the farm and freshwater mixing during drought etc.(Muralidhar et al., 2012). These adaptive measures are mostly autonomous (i.e. spontaneous response to environmental changes)(Shelton, 2014).

In order to increase shrimp farmers' resilience to the climate change it is essential to provide planned adaptations such as financial support, technical assistance, research, extension services and training. Both the government and non-government organizations (NGOs) are providing training to the shrimp farmers to enhance their resilience of shrimp farming in coastal Bangladesh. However, the extent of the training facility is very limited and does not include instructions for adaptations to climate change. The trainers only provide instructions on the management of emerging effects of climatic changes in response to the questions of the participants during training sessions. Effective training programs can increase yield in aquaculture and enhance consequent income generation(Alam et al., 2005; Thompson et al., 2006). Therefore, training support is essential for betterment of shrimp farmers and trainings need to include adaptations to climate change to increase the sustainability of this aquaculture in southwest coastal Bangladesh. Therefore, it is necessary to understand the knowledge level of the shrimp farmers and their training needs to adapt with the emerging changes of climatic variables. This study aimed to assess the competence level of shrimp farmers in climate change adaptation and to identify their training needs. The findings of this study may help relevant organizations to plan and implement better training programs to promote sustainable development of shrimp farming in coastal Bangladesh.

\section{Methodology}

\section{Study area}

This study was conducted in Shyamnagarsub-district under Satkhira District (Figure 1). The sub-district occupies an area of $1968 \mathrm{~km}^{2}$ of which $1622 \mathrm{~km}^{2}$ belongs to the Sundarbans mangrove forest. It is located between $21^{\circ} 37^{\prime} 37^{\prime \prime}$ and $22^{\circ} 24^{\prime} 7^{\prime \prime}$ north latitudes and between 88 $59^{\prime} 49^{\prime \prime}$ and $89^{\circ} 22^{\prime} 34^{\prime \prime}$ east longitudes. The sub-district is bounded by Kaliganj and Assasunisub-districts on the north, Koyrasub-district of Khulna district on the east, Bay of Bengal on the south and West Bengal (India) on the west. It holds a population of 318254 (Bangladesh Bureau of Statistics (BBS), 2011). Among the 12 unions of Shyamnagar sub-district, Kaikhali and Ramjannagar unions were selected for the study. These two unions were chosen because both of the unions have substantial training coverage (both GO and NGO) and shrimp farming is the prime livelihood activity. Kaikhali Union holds an area of $44 \mathrm{~km}^{2}$. It is situated on the bank of Palnadi River which separated the union from India and Sundarban. This union is about $20 \mathrm{~km}$ far from sub-district head quarter and $75 \mathrm{~km}$ from Satkhira district head quarter. The Ramjannagar union is just adjacent to the Kaikhali Union. It holds an area of $39 \mathrm{~km}^{2}$. The union is bounded by Munshi gong union on the North and east, Isshawripur union on the west and Malonchi River and Sundarbans on the South. The Malonchi River separates the union from Sundarban. The union is about $15 \mathrm{~km}$ from sub-district head quarter and $70 \mathrm{~km}$ from Satkhira district head quarter. 


\section{Data collection}

This study conducted 100 questionnaire survey for the assessment of training needs of the shrimp farmers regarding the adaptation to climate change. The respondents were divided into two groups. Group A included 50 shrimp farmers who have recently participated in shrimp farming related training and group B included 50 shrimp farmers who have never participated in any shrimp farming related training program and do not have communication with the shrimp farmers having training support. The 50 shrimp farmers of group A were selected in a way so that 25 of them had recently participated in government organizations provided training and another 25 of them had recently participated in non-government organization provided training. Selection of these shrimp farmers were based on a random selection from a preliminary list made with the help of Upazila Fisheries Office and local office of WorldFish (an international organization providing shrimp farming training in the study area).

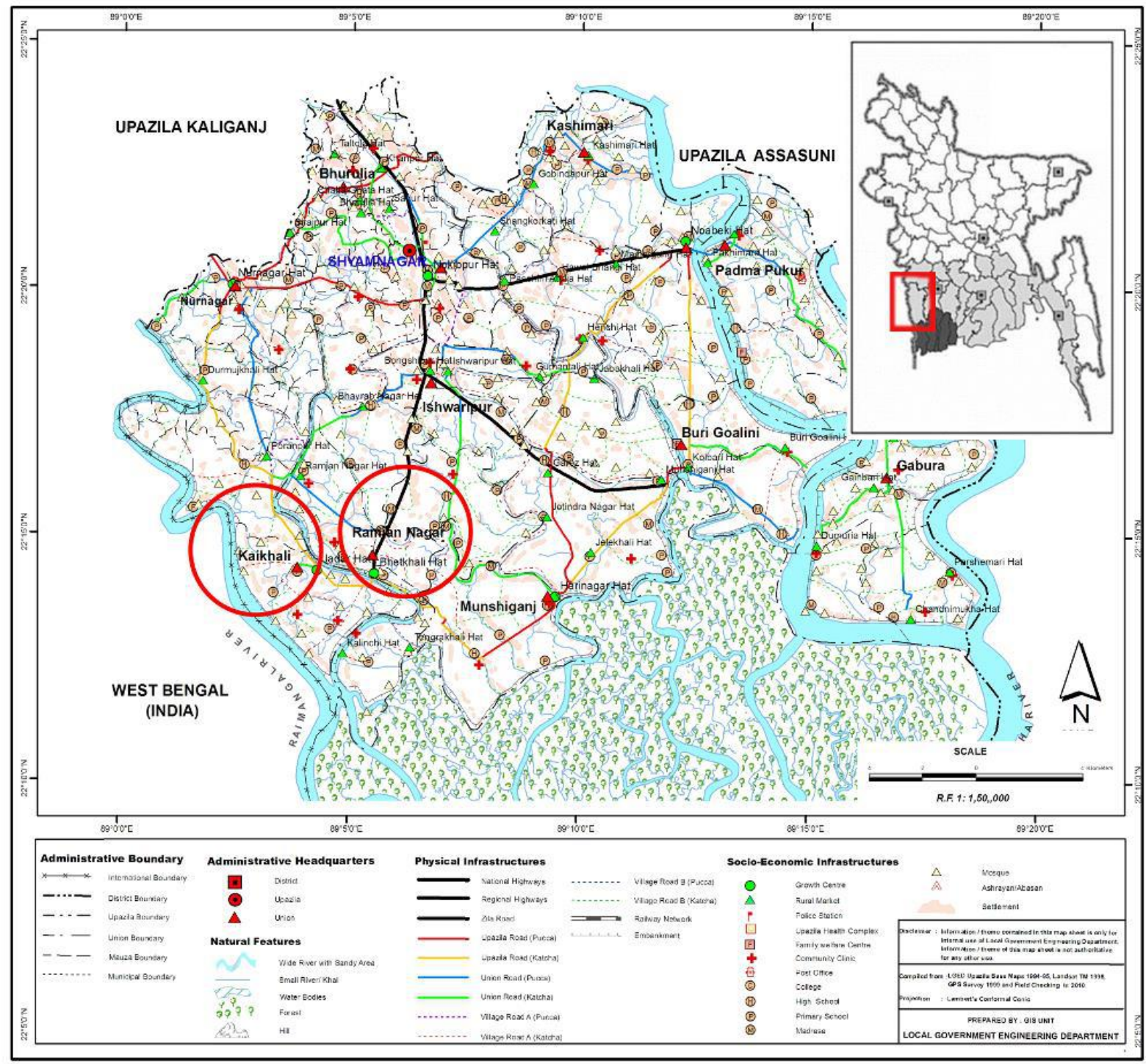

Source: modified after Local Government Engineering Department (LGED),

Figure 1 Map of the study area. The red circles indicate the unions where questionnaire survey was conducted. 
The questionnaire was divided into three sections. The first section contained questions on the socioeconomic characteristics of the respondents, second section contained questions on the competence and training needs of the shrimp farmers, and the third section contained questions regarding the yield of shrimp. To assess both the competence and importance levels regarding climate change adaptation related management, a scale of 1 to 3 were used (where $1=$ low, $2=$ intermediate and 3 =high). The climate change related management issues were not included as separate section in the existing training manuals. Therefore, the questions were organized upon existing management practice of the local shrimp farmers for the impacts related to changes in climatic variables. Six climatic variables (temperature, drought, salinity, rainfall, flood and cyclone) were identified from relevant literatures. Adaptation measures taken by local shrimp farmers for the impacts of changes of these climatic variables were identified through discussion with the experts' (upazila fisheries officer, assistant upazila fisheries officer, shrimp farming related trainers from both government and non-government organizations, Local Extension Agent for Fisheries (LEAF), experienced shrimp farmers). The questionnaire was pre-tested in the study area and revised before final survey. The questionnaire survey was conducted by trained enumerators.

A total of 20 key informant interviews were conducted to get better clarification of the facts found from the questionnaire survey and to assess the present status of the training programs. The study considered upazila fisheries officers, assistant upazila fisheries officer, responsible personnel of the training providing organizations, shrimp farming related trainers from both government and non-government organizations, experienced shrimp farmers (president or secretary of the gher owner's association, educated shrimp farmers, and school or college teachers) as key informants.

\section{Data analysis}

Independent sample t-test and Mann-Whitney $U$ test was used to compare the differences among the socioeconomic variables between the groups. Only the data of age shows normal distribution, while the data of other variables failed to meet the assumptions of normal distribution. Hence the data of age was tested using the independent sample t-test and the other variables were analyzed using the Mann-Whitney U test. Independent sample t-test was used to assess the difference in total competence level between the groups.

Borich Needs Assessment Model (Borich, 1980) was used for evaluating and ranking training needs of shrimp farmers to adapt with climate change. The model is one of the most widely used models in agricultural education and agricultural extension with regard to need assessment of agricultural teachers, extension agents and farmers (Hashemi et al., 2009). It calculates weighted discrepancy score (WDS) using the following formula:

WDS $=$ DS*MIL $\ldots \ldots \ldots$ (i)

WDS $=($ IL-CL) $*$ MIL ........ (ii)

Where WDS $=$ weighted discrepancy score, $\mathrm{DS}=$ discrepancy score, $\mathrm{IL}=$ farmer-determined level of importance of each competency, $\mathrm{CL}=$ farmer-determined level of knowledge of each competency, $\mathrm{MIL}=$ mean importance rating for each competency.

The climate change adaptation issues were ranked based on the WDS scores to understand the priority of the issues for future training programs. A scale of 1 to 3 was used for calculation of both competence and importance level of shrimp farmers, where 1 means low, 2 means intermediate and 3 means high competence and importance. All data were analyzed using the SPSS for Windows, version 16.0 and Microsoft Excel. 


\section{Results and discussion}

\section{Socio-economic profile of the respondents}

The socioeconomic profile of the two groups of shrimp farmers is presented in Table 1. Mean ages of shrimp farmers of group A, and group B were 41.06, and 40.1 years, respectively (Table 1). Shrimp farmers of both groups had secondary levels of academic education with average education periods 8.92 and 7.04 years for group A and group B, respectively. Group A had relatively high age, education, farming experience, off farm income, annual household expenditure, shrimp production and finfish production, compared to group B. However, except shrimp yield $(\mathrm{P}<0.01)$ none of the differences were significant $(\mathrm{P}>0.05)$. According to the key informants, the higher yield of shrimp and finfish in group A may be attributed to better cultivation practices because of the training.

Table 1 Comparison of socio-economic variables between the two groups of shrimp farmers.

\begin{tabular}{llll}
\hline Variables & Group A & Group B & t/Mann-Whitney U test value \\
\hline Age (years) & 41.06 & 40.1 & 0.674 \\
Education (years) & 8.92 & 7.04 & 0.225 \\
Family members (numbers) & 5.62 & 5.72 & 0.839 \\
Shrimp farming experience (years) & 17.06 & 16.24 & 0.417 \\
Shrimp farm area (hectares) & 2.68 & 2.80 & 0.821 \\
Off farm income amount (BDT) & 69333 & 65112 & 0.421 \\
Annual household expenditure (BDT) & 154288 & 140246 & 0.517 \\
Shrimp yield (Kg/ha/year) & 476 & 261 & $0.000^{*}$ \\
Finfish yield (Kg/ha/year) & 192 & 185 & 0.934 \\
\hline
\end{tabular}

Note:*Sampling sources differed significantly at $\mathrm{p}<0.0005$

\section{Competence and training needs of shrimp farmers on climate change adaptation}

Table 2 shows the total competence on climate change related management of shrimp farming for the two groups of shrimp farmers. Both group A and group B rated the climate change related management as highly important. The total mean competence of the shrimp farmers of group A and group B were 2.02, 1.90 respectively, suggesting that shrimp farmers of group A have higher competence level than group $B$. Moreover significant differences $(\mathrm{P}=0.008, \mathrm{P}<0.05)$ were found in total competence between the groups. The WDS scores of group B was higher than group A, which indicates that group B wanted to participate in climate change related training more than group A. From the review of the training manuals and key informants interview it was found that there was no separate training sessions or programs for climate change related management in shrimp farming. However, partial and indirect instructions (like strengthening embankment, increasing pond depth, water exchange etc.) were communicated to the shrimp famers upon their queries during the shrimp farming training. 
Table 2 Comparison of total competence on climate change related management between the two groups of shrimp farmers.

\begin{tabular}{lllll}
\hline Group & Mean importance level & Mean competence level & DS score & WDS \\
\hline Group A & 2.88 & 2.02 & 0.86 & 2.47 \\
Group B & 2.81 & 1.90 & 0.91 & 2.56 \\
\hline
\end{tabular}

The perceived level of importance, competence, standard deviation, discrepancy score, and weighted discrepancy score is summarized in Table 3. Compared to competence scores, both the groups had higher importance scores in all the climate change adaptation issues. However, group A had more competence and lesser need to participate in training for all the issues of climate change adaptation related management. This may be attributed to the training experiences of shrimp farmers of group A.

For the management of excessive temperature, the importance level for both the groups were same (2.92) but group A had higher competence level (2.08), compared to group B (2.04). This higher competence level of group A may be attributed to the participation of group A shrimp farmers in the training programs. It was found from the key informant interviews that simple techniques like water exchange from the nearby water source and ground water irrigation in response to extreme weather condition are usually suggested in the training programs. Though these instructions were not aimed to combat the adverse impact of excessive temperature, rather these were aimed to other purposes like water quality maintenance. Besides, group B shrimp farmers had more need to participate in training for management of excessive temperature than group A shrimp farmers indicated by higher WDS score of group B.

Both the groups also reported similar importance level in management for drought (2.92). Like management for excessive temperature, group A had more knowledge (competence) and relatively less need for training in management of drought, compared to group B. These findings again may be the result of the participation of group A shrimp farmers in the training programs.

Table 3 Perception of importance and competence level for climate change related management in shrimp farming.

\begin{tabular}{|c|c|c|c|c|c|c|c|}
\hline \multirow{2}{*}{$\begin{array}{l}\text { Management } \\
\text { issues }\end{array}$} & \multirow[t]{2}{*}{ Group no. } & \multicolumn{2}{|c|}{ Importance level } & \multicolumn{2}{|c|}{ Importance level } & \multirow[t]{2}{*}{ DS Score } & \multirow[t]{2}{*}{ WDS } \\
\hline & & Mean & SD & Mean & SD & & \\
\hline \multirow{2}{*}{ Temperature } & Group A & 2.92 & 0.34 & 2.08 & 0.34 & 0.84 & 2.45 \\
\hline & Group B & 2.92 & 0.39 & 2.04 & 0.44 & 0.88 & 2.57 \\
\hline \multirow{2}{*}{ Drought } & Group A & 2.92 & 0.34 & 2.04 & 0.28 & 0.88 & 2.56 \\
\hline & Group B & 2.92 & 0.34 & 1.96 & 0.30 & 0.96 & 2.80 \\
\hline \multirow{2}{*}{ Salinity } & Group A & 2.98 & 0.14 & 1.98 & 0.37 & 1.00 & 2.98 \\
\hline & Group B & 2.80 & 0.40 & 1.78 & 0.41 & 1.02 & 2.86 \\
\hline \multirow{2}{*}{ Rainfall } & Group A & 2.90 & 0.36 & 2.00 & 0.45 & 0.90 & 2.61 \\
\hline & Group B & 2.80 & 0.45 & 1.88 & 0.32 & 0.92 & 2.58 \\
\hline \multirow{2}{*}{ Flood } & Group A & 2.88 & 0.43 & 2.10 & 0.50 & 0.78 & 2.25 \\
\hline & Group B & 2.80 & 0.40 & 2.00 & 0.35 & 0.80 & 2.24 \\
\hline \multirow{2}{*}{ Cyclone } & Group A & 2.66 & 0.66 & 1.92 & 0.65 & 0.74 & 1.96 \\
\hline & Group B & 2.60 & 0.66 & 1.72 & 0.49 & 0.88 & 2.29 \\
\hline
\end{tabular}


Shrimp farmers of group A reported the highest importance level in management of salinity fluctuation. The competence scores of group A and B were 1.98 and 1.78 respectively. According to field observation and key informant interviews, salinity increase or excessive salinity is a major problem for shrimp farming in the study area. Salinity level increases mainly in the dry season, which hampers shrimp growth. Paul and Vogl (2012) also found that during dry season high water salinity in Satkhira district hardly makes the area suitable for shrimp cultivation. In the training programs instructions were provided like ground water irrigation to combat the effect of high salinity. This may be the cause of higher competence level of group A shrimp farmers, compared to group B.

Both of the groups had higher importance for the management of heavy rainfall (importance level for group A and B were respectively 2.90 and 2.80). According to the key informants, heavy rain have increased in last decades. Therefore, shrimp farmers are more careful about the management of rainfall. Adaptation measures like strengthening earthen dyke, netting around the pond, discharge of excess water are the common adaptive measures to combat the effect of heavy rainfall. These instructions were provided to the shrimp farmers in the training programs, which may be the reason for the higher competence level of group A shrimp farmers (2.00), compared to group B shrimp farmers (1.88).

Importance score in management for flood is also higher for both of the groups (respectively 2.88 and 2.80 for group A and B) but it is lower compared to other issues. According to the key informants flood is not as frequent as the other issues like excessive temperature, drought, high salinity and heavy rainfall. This may be the cause of lower importance scores of both the groups in management of flood.

Both of the groups reported the least importance level in management for cyclone compared to other issues, still the importance were higher as per the importance score (respectively 2.66 and 2.60 for group A and group B). According to the key informants, during cyclone shrimp farmers' first priority is to save their lives and find safe shelter. This may be the cause of the least importance and least competence in this issue.

Both the groups reported low competence level in management for cyclone and management for fluctuation of salinity, indicating their knowledge or competence gaps to combat the adverse impacts associated with the changes of these climatic variables. Moreover group B also reported low competence level in management of drought and management heavy rainfall. Group A reported the highest competence level in management of flooding, while group B reported the highest competence level in management for excessive temperature.

For both of group A and group B, WDS scores were highest in management of fluctuation of salinity (Table 3 ), which indicates their highest need for training regarding the management of salinity fluctuations. Salinity increase or excessive salinity occurs during the dry season, this hampers shrimp growth. According to key informants, water exchange is the easiest solution for reducing salinity. However, most of the shrimp farmers don't get good access to tidal water because of poor water management in this area. Ground water irrigation is an alternative way to decrease salinity level in the ponds but only a few shrimp farmers are able to bear the cost of ground water irrigation. Therefore, they need other adaptation measures to combat this adverse effect. We found the least WDS scores in management of cyclone and management of flood related impacts for group A and group B, respectively. These lowest WDS scores revealed the relatively lowest need of the shrimp farmers to attend in a training program for these issues. Flood and cyclone are not as frequent as the other variables of climate change and during these events shrimp farmers are more concerned to find safe shelter for their family.

The ranking of training priorities based on WDS scores is summarized in Table 4. Irrespective of their participation in training, the highest rank for both group A and group B shrimp farmers were found in management of fluctuation of salinity. So both the groups had the highest need of training support for management of salinity fluctuation. Therefore, different adaptive measures to combat the adverse impact of high salinity could be included in the training. The second and third highest WDS scores for group A were in management for heavy rainfall and management of drought, respectively. Conversely, for group A, the second and third highest WDS scores were found in management of drought and management for heavy rainfall, 
respectively. The study area is a drought prone area(Ali, 2006). According to key informants, heavy rainfall has increased in recent decades. Therefore, shrimp farmers in this area are more susceptible to drought and heavy rainfall. Consequently, they have higher need for training support on the management of drought and heavy rainfall related impacts. While group A showed the two lowest WDS scores in management for cyclone and management of flood, respectively and group B reported the two lowest WDS scores in management of flood and cyclone, respectively.

Table 4 Ranking of training priorities between the two groups of shrimp farmers.

\begin{tabular}{lcc}
\hline Issues & Group A & Group B \\
\hline Management for excessive temperature & 4 & 4 \\
Management for drought & 3 & 2 \\
Management for fluctuation of salinity & 1 & 1 \\
Management for heavy rainfall & 2 & 3 \\
Management for flood & 5 & 6 \\
Management for cyclone & 6 & 5 \\
\hline
\end{tabular}

\section{Conclusions}

This study assessed the climate change management related competence level and training needs of shrimp farmers of southwest coastal Bangladesh. Both the trained and non-trained shrimp farmers imposed higher importance on management of impacts of climate change. Non-trained shrimp farmers had moderate level of competence to adapt with the impacts of climate change, whereas trained shrimp farmers exhibited high competence. Therefore, training support for shrimp farming may improve the adaptation capacity of shrimp farmers. Although, the competence of trained shrimp farmers was higher than that of the non-trained shrimp farmers, it was still lower than their importance level. This indicates the necessity to improve the quality of existing training to better adapt with the impacts of climate change. As the existing training manuals do not include climate change adaptation issues, existing training facilities are not sufficient to provide adequate information on climate change adaption for shrimp farming. It is highly necessary to include a separate section on adaption to climate change in the existing training manuals as the shrimp farmers have higher need for climate change adaptation related aspects. Among the climate change issues, more emphasis is necessary on management of salinity fluctuation, heavy rainfall and drought. Incorporation of climate change adaption in existing training and extending the training support for the shrimp farmers may contribute in sustainability of shrimp aquaculture in southwest coastal Bangladesh.

\section{Acknowledgements}

We express our sincere gratitude to the shrimp farmers and relevant professionals who extended their cooperation during data collection. This work was carried out under the Collaborative Adaptation Research Initiative in Africa and Asia (CARIAA), with financial support from the UK Government's Department for International Development (DFID) and the International Development Research Centre (IDRC), Canada [Grant number: IDRC 107642]. The views expressed in this work are those of the creators and do not necessarily represent those of DFID and IDRC or its Board of Governors. 


\section{References}

Afroz, T., Alam, S., 2013. Sustainable shrimp farming in Bangladesh: A quest for an Integrated Coastal Zone Management. Ocean Coast. Manag. 71, 275-283. doi:10.1016/j.ocecoaman.2012.10.006

Ahmed, N., 2013. Linking prawn and shrimp farming towards a green economy in Bangladesh: Confronting climate change. Ocean Coast. Manag. doi:10.1016/j.ocecoaman.2013.01.002

Ahmed, N., Glaser, M., 2016. Can "Integrated Multi-Trophic Aquaculture (IMTA)" adapt to climate change in coastal Bangladesh? Ocean Coast. Manag. doi:10.1016/j.ocecoaman.2016.08.017

Alam, S.M.N., Lin, C.K., Yakupitiyage, A., Demaine, H., Phillips, M.J., 2005. Compliance of Bangladesh shrimp culture with FAO code of conduct for responsible fisheries: a development challenge. Ocean Coast. Manag. 48, 177-188. doi:10.1016/j.ocecoaman.2005.01.001

Ali, A.M.S., 2006. Rice to shrimp: Land use/land cover changes and soil degradation in Southwestern Bangladesh. Land use policy 23, 421-435. doi:10.1016/j.landusepol.2005.02.001

Azad, A.K., Jensen, K.R., Lin, C.K., 2009. Coastal aquaculture development in Bangladesh: Unsustainable and sustainable experiences. Environ. Manage. doi:10.1007/s00267-009-9356-y

Bangladesh Bureau of Statistics (BBS), 2011. Statistical yearbook of Bangladesh-2010. Government of Bangladesh, Dhaka.

Borich, G.D., 1980. A needs assessment model for conducting follow-up studies. J. Teach. Educ. 31, 39-42.

Gammage, S., Swanberg, K., Khandkar, M., Hassan, M.Z., Zobair, M., Muzareba, A.M., 2006. A pro-poor analysis of the shrimp sector in Bangladesh. USAID.

Harmeling, S., Eckstein, D., 2012. Global Climate Risk Index 2013. Who Suffers Most from Extreme Weather Events? Brief. Pap. Ger.

Hashemi, S.M., Hosseini, S.M., Damalas, C.A., 2009. Farmers' competence and training needs on pest management practices: Participation in extension workshops. Crop Prot. 28, 934-939. doi:10.1016/j.cropro.2009.07.007

Hossain, M.S., Uddin, M.J., Fakhruddin, A.N.M., 2013. Impacts of shrimp farming on the coastal environment of Bangladesh and approach for management. Rev. Environ. Sci. Bio/Technology 12, 313-332. doi:10.1007/s11157-013-9311-5

Kreft, S., Eckstein, D., 2013. Global Climate Risk Index 2014. Who Suffers Most from Extreme Weather Events? Think Tank Res. 28.

Muralidhar, M., Kumaran, M., Jayanthi, M., Muniyandi, B., Ponniah, A.G., Nagothu, U.S., White, P., Eknath, A., 2012. Case study on the impacts of climate change on shrimp farming and developing adaptation measures for small-scale shrimp farmers in Krishna District, Andhra Pradesh, India. Andhra Pradesh.

Paul, B.G., Vogl, C.R., 2012. Key performance characteristics of organic shrimp aquaculture in southwest Bangladesh. Sustainability 4, 995-1012. doi:10.3390/su4050995

Shelton, C., 2014. Climate change adaptation in fisheries and aquaculture-compilation of initial examples.

Sohel, M.S.I., Ullah, M.H., 2012. Ecohydrology: A framework for overcoming the environmental impacts of shrimp aquaculture on the coastal zone of Bangladesh. Ocean Coast. Manag. 63, 67-78. doi:10.1016/j.ocecoaman.2012.03.014

Swapan, M.S.H., Gavin, M., 2011. A desert in the delta: participatory assessment of changing livelihoods induced by commercial shrimp farming in Southwest Bangladesh. Ocean Coast. Manag. 54, 45-54. doi:10.1016/j.ocecoaman.2010.10.011

Thompson, P.M., Firoz Khan, A.K.M., Sultana, P., 2006. Comparison of aquaculture extension impacts in Bangladesh. Aquac. Econ. Manag. 10, 15-31. doi:10.1080/13657300500315786

USAID, 2006. pro-poor analysis of the shrimp sector in Bangladesh, Greater Access to Trade Expansion (GATE) Project; Development Training Services, The United States Agency for International Development: Arlington, TX, USA. Arlington, TX. 